Published in final edited form as:

Dig Dis Sci. 2018 June ; 63(6): 1572-1582. doi:10.1007/s10620-018-5021-8.

\title{
Inflammatory Bowel Diseases can Adversely Impact Domains of Sexual Function such as Satisfaction with Sex Life
}

\author{
Swathi Eluri, MD, MSCR ${ }^{1}$, Raymond K. Cross, MD, MS ${ }^{2}$, Christopher Martin, MSPH ${ }^{1}$, Kevin \\ P. Weinfurt, $\mathrm{PhD}^{3}$, Kathryn E. Flynn, $\mathrm{PhD}^{4}$, Millie D. Long, MD, $\mathrm{MPH}^{1}$, Wenli Chen, MS, $\mathrm{MA}^{1}$, \\ Kristen Anton, $\mathbf{M S}^{1}$, Robert S. Sandler, MD, MPH ${ }^{1}$, and Michael D. Kappelman, MD, MPH ${ }^{1}$ \\ ${ }^{1}$ University of North Carolina at Chapel Hill, Chapel Hill, NC \\ 2University of Maryland School of Medicine, Baltimore, MD \\ ${ }^{3}$ Duke University School of Medicine, Durham, NC \\ ${ }^{4}$ Medical College of Wisconsin, Milwaukee, WI
}

\begin{abstract}
Background-Aspects of sexual health, which can be adversely affected by chronic disease, have been inadequately explored in inflammatory bowel disease (IBD).
\end{abstract}

\begin{abstract}
Aims-We evaluated patient-reported interest in sexual activity and satisfaction with sex life in a large cohort of IBD patients.

Methods-We conducted a cross sectional study within the Crohn's and Colitis Foundation Partners Internet cohort. Sequential participants completed a 6-question supplemental online survey to examine sexual interest and satisfaction using the Patient Reported Outcome Measurement Information System ${ }^{\circledR}$ (PROMIS $\left.{ }^{\circledR}\right)$ Sexual Function and Satisfaction (SexFS) measures. One-sample t-tests were used to compare interest and satisfaction scores to general population norms.
\end{abstract}

\begin{abstract}
Results-Among 2569 individuals, 1639 had Crohn's disease (CD), 930 had ulcerative colitis (UC) or indeterminate colitis, and 71\% were women. Mean PROMIS scores for sexual interest were comparable to the general United States (US) population in men (CD: 49 and UC: 48 vs. population mean 50) and women (CD: 41 and UC: 40 vs. population mean 42). However, sexual satisfaction scores were lower than the US population in men (CD: 48 and UC: 48 vs. 51) and women (CD: 47 and UC: 46 vs. 49), p<0.01 for both. Older age, disease activity, depression, anxiety, and pain were associated with lower interest and satisfaction and lowered IBD-specific quality of life.
\end{abstract}

\footnotetext{
Corresponding Author: Swathi Eluri, MD, MSCR Division of Gastroenterology and Hepatology, University of North Carolina School of Medicine, 4119B Bioinformatics Building, 130 Mason Farm Road, Chapel Hill, NC 27599-7080; Phone: (919) 843-7893; Fax: (919) 966-6842; swathi@med.unc.edu.

Raymond Cross: University of Maryland Medical Center, 22 S Green St, Baltimore, MD 21201. rcross@medicine.umaryland.edu Kevin Weinfurt: Duke Clinical Research Institute, 2400 Pratt St, Durham, NC 27705.: kevin.weinfurt@duke.edu Kathryn Flynn: Medical College of Wisconsin, 8701 Watertown Plank Rd, Milwaukee, WI 53226. kflynn@mcw.edu

Christopher Martin: chris_martin@med.unc.edu; Millie Long: millie_long@med.unc.edu; Wenli Chen: wenli_chen@med.unc.edu; Kristen Anton: Kristen.Anton@dartmouth.edu; Robert Sandler: robert_sandler@med.unc.edu; Michael Kappelman: michael_kappelman@med.unc.edu, Address: 4119B Bioinformatics Building, 130 Mason Farm Road, Chapel Hill, NC 27599-7080

Disclosures: No authors have a conflict of interest to disclose in relation to this article.
} 
Conclusions-IBD patients in a large online survey had similar levels of sexual interest but decreased sexual satisfaction compared to the general population. Exploring these sexual health domains during clinical encounters can aid in improving IBD quality of life.

\section{Keywords}

sexual dysfunctions; physiological; sexual health; inflammatory bowel disease; quality of life

\section{INTRODUCTION}

Patients with inflammatory bowel disease (IBD), including Crohn's disease (CD) and ulcerative colitis (UC), can have impaired quality of life as a result of depression [1], anxiety [2], and fatigue [3-4]. Sexual interest and satisfaction are other important aspects affecting quality of life, but it is unclear how these domains are impacted by IBD. Existing reports have been mixed, with some studies showing no differences in sexual activity [5] or frequency of sexual intercourse [6] between IBD patients and controls.

Conversely, one of the earliest studies reported that nearly a quarter of female CD patients completely abstained from sexual activities primarily due to abdominal pain, diarrhea, and fear of fecal incontience [7]. Other studies [8-10] have also shown that sexual dysfunction is reported in approximately $50 \%$ of women with IBD. In both men and women, depression appears to be a major driver of impaired sexual activity [5,11,12].

While these studies quantified differences in sexual function broadly and identified some contributing factors to decreased function, few studies have focused on particular aspects of sexual health such as sexual interest and sexual satisfaction among IBD patients. Marin et al. showed that women reported worsened sexual desire and satisfaction compared to men after being diagnosed with IBD [10]. Factors associated with lower levels of sexual satisfaction in women are longer duration of $\mathrm{CD}$, presence of complex fistulae or abscesses, and impaired pelvic floor function [13]. Another report described higher levels of desire and satisfaction amongst IBD patients following proctocolectomy or proctectomy in male patients and ileal pouch anal anastomosis (IPAA) in female patients [14].

Given the limited literature on sexual health in IBD and the importance of understanding this domain to improve the overall psychosocial wellbeing of IBD patients, we aimed to evaluate interest in sexual activity and satisfaction with sex life among participants in the Crohn's and Colitis Foundation Partners Internet cohort using the Patient Reported Outcomes Measurement Information System ${ }^{\circledR}$ (PROMIS ${ }^{\circledR}$ ) Sexual Function and Satisfaction (SexFS) measures [15-18], which have undergone rigorous development and validation based on qualitative research and psychometric evaluation in a large US sample [19-21]. We hypothesized that among IBD patients, female sex, depression, current ostomy, prior IPAA, perianal disease, and active steroid use would be associated with lower interest in sexual activity and satisfaction with sex life. 


\section{METHODS}

\section{Study Population}

Crohn's and Colitis Foundation Partners is a longitudinal Internet-based cohort of patients with IBD. The development of the cohort has been described in detail previously [22]. Participants older than 18 years with a self-reported diagnosis of $\mathrm{UC}, \mathrm{CD}$, or indeterminate colitis (IC) were recruited through the Crohn's and Colitis Foundation email rosters, the Crohn's and Colitis Foundation website, social media outlets, and at educational and fundraising events. All participants completed a baseline survey including demographic information and questions about their IBD history, symptoms, and medication use. Followup questionnaires every 6 months tracked changes in disease treatments, symptoms, and other patient reported outcomes (PROs). A prior validation study demonstrated $97 \%$ accuracy of self-reported diagnoses of CD or UC in the cohort [23].

For this study, consecutive survey respondents between February and June of 2012 were invited to complete an optional 6 question supplemental survey in addition to their baseline or regularly scheduled follow up survey (Supplementary Table). The items measured interest in sexual activity, satisfaction with sex life, and when applicable, the impact of having an ostomy or IBD symptoms on satisfaction with sex life. The study protocol was reviewed and approved by the Institutional Review Board of the University of North Carolina.

\section{PROMIS SexFS Assessments}

The Interest in Sexual Activity and Satisfaction with Sex Life scales were developed and validated as part of the NIH PROMIS initiative. The PROMIS Sexual Function and Satisfaction item bank has undergone rigorous development and validation based on qualitative research and item response theory similar to all PROMIS measures [15$17,24,25]$. It was designed to be used in diverse populations, both with and without chronic disease. As such, the SexFS items are not disease-specific, though items are available that ask about disease- and symptom-specific effects on satisfaction. All items ask about sexual function and satisfaction in the past 30 days. For measuring interest and satisfaction in a sample of both men and women, PROMIS offers advantages over other measures in that it uses the same scales and scoring for both men and women. Items were scored according to the strategy of SexFS measure (version 2.0).

Higher scores on the SexFS indicate more of the domain being measured. Hence, higher scores for the domains of Interest in Sexual Activity and Satisfaction with Sex Life imply higher interest and greater satisfaction. Scores are expressed as t-scores, where the mean \pm SD for the general U.S. sexually active adult population is $50 \pm 10$. US population norms for SexFS measures differ by sex [17], based on a nationally-representative sample weighted to the 2012 Current Population Survey of 1758 men and 1757 women, with mean age 47 (SD 17). The mean \pm SD for sexual interest is $50 \pm 10$ for males and $42 \pm 14$ for females. Because of differential item functioning based on recent sexual activity [17], the sexual satisfaction measure is only scored in persons who were sexually active in the past 30 days. Sex-specific population means for satisfaction are $51 \pm 9$ and $49 \pm 11$ for males and females, 
respectively. We considered a difference in score of 2-4 as a clinically meaningful difference similar to other PROMIS measures [26-28].

\section{Other Self-Report Assessments}

The Short IBD Questionnaire (SIBDQ) was administered as a disease-specific measure of HRQOL [29]. Disease activity was evaluated using validated measures such as the short Crohn's Disease Activity Index (sCDAI) for CD [30] and the Simple Clinical Colitis Activity Index (SCCAI) for UC and IC. A sCDAI $<150$ is categorized as clinical remission for $\mathrm{CD}$ and an SCCAI $\mathcal{S}$ is categorized as clinical remission for UC and active disease as values above this threshold [30,31]. Surveys also included PROMIS items from the depression, anxiety, fatigue, sleep disturbance, and pain interference item banks. These PROMIS domains are expressed as t-scores where the mean \pm SD for the general U.S. adult population is $50 \pm 10$. We also measured patient demographics, IBD medication use such as oral 5-aminosalicylates, prednisone, immunomodulators, and biologic therapies (infliximab, adalimumab, certolizumab pegol, golimumab, and natalizumab), perianal disease and pouch and ostomy status by self-report.

\section{Statistical Analysis}

For each domain, one-sample $t$-tests were used to compare means of interest and satisfaction scores to the corresponding general sex-specific population means within groups of UC and CD patients. Chi-square tests and ANOVA F-statistics were used to assess the relationship between interest and satisfaction t-scores and patient demographics, disease activity, quartiles of SIBDQ scores, current corticosteroid use, and categorical disease characteristics (current ostomy, prior IPAA, perianal disease).

In addition, mean PROMIS scores for interest and satisfaction were compared across quartiles (as these scores were not normally distributed) of disease activity, SIBDQ scores, and other PROMIS measures (depression, anxiety, fatigue, sleep, pain) using a nonparametric test of trend for the ranks across ordered groups. Comparator variables such as disease activity, steroid use, ostomy/IPAA, and active perianal disease were dichotomized and mean interest and satisfaction scores were compared between the two groups for each variable using Student's t-tests. Analyses were stratified by sex and disease type (UC/IC or $\mathrm{CD}$ ). Finally, a multivariable analysis was performed for sexual interest and satisfaction scores in UC and CD patients adjusted for sex, age, race, ethnicity, education, disease activity scores, and PROMIS measures for (depression, anxiety, fatigue, sleep). Statistical analyses were performed using SAS version 9.4.

\section{RESULTS}

\section{Study Population}

Of 3811 individuals who were offered the optional online survey on sexual interest and satisfaction, 2581 (68\%) completed the survey. This response rate was comparable to other surveys administered through the CCFA Partners to a subset of patients, with response rates ranging from $59-71 \%$. Twelve respondents whose sex was unknown were excluded, leaving a total 2569 individuals for analysis. In this sample, 1639 (64\%) had CD and $930(36 \%)$ had 
UC or IC (Table 1). The mean \pm SD age of respondents was $42 \pm 14$ years and $71 \%$ percent were female. The majority was white $(91 \%)$ and had a college or graduate degree. The mean time of disease duration was $13 \pm 11$ years. Seventy-seven percent of the sample was sexually active with a similar proportion among men (78\%) and women (77\%), and subjects with CD (76\%) and UC (78\%). Additional characteristics of the study population are provided in Table 1.

\section{Interest in Sexual Activity and Satisfaction with Sex Life}

The mean PROMIS score for interest in sexual activity was 41 for CD women and 40 for UC women, comparable to the US general population mean of 42 (Table 2). However, satisfaction with sex life was lower for women with IBD (mean T scores of 47 for CD and 46 for UC) compared to the population mean of $49, \mathrm{p}<0.01$. Similar to women, levels of interest in sexual activity in men with IBD were comparable to the general population (mean T scores for CD: 49 and UC: 50 vs. population mean 50); however, mean sexual satisfaction $\mathrm{T}$ scores were 3 points lower in men with IBD than the general population (CD and UC: 48 vs. population mean 51, $\mathrm{p}<0.01$ ). Based on the established MID for PROMIS measures (2 to 4 ), the difference in sexual interest among men and women with IBD versus the general population are small but clinically meaningful.

The relationships between sexual interest and satisfaction scores and age, race/ethnicity, and educational status are shown in Tables 3a and 3b. Scores for both domains decreased with increasing age in men and women, except for sexual satisfaction in CD men (non-significant trend observed) and UC women. No consistent differences were observed for race/ethnicity. Associations with educational level were also mixed, though most comparisons showed direct associations between sexual interest and satisfaction and educational level.

In multivariable analysis, factors associated with lower sexual interest scores in UC and CD patients were female sex, increasing age, and fatigue ( $\mathrm{p}<0.05$ for all). In addition, increasing anxiety was also found to be significantly associated with lower sexual interest scores in UC patients $(\mathrm{p}=0.03)$. Factors associated with lower satisfaction scores in both $\mathrm{UC}$ and $\mathrm{CD}$ were female sex, increasing age, anxiety, and sleep disturbance, $(\mathrm{p}<0.05$ for all).

\section{Associations with Disease Severity, HRQOL, and other PROs}

As expected, mean PROMIS scores for interest in sexual activity and satisfaction with sex life were lower with increasing levels of disease activity, with the exception of UC women (Tables $4 \mathrm{a}$ and $4 \mathrm{~b}$ ). The magnitude of decreased interest and satisfaction with more severe disease activity was greater for men with a larger difference in PROMIS scores between the lowest quartile (Q1) and highest quartile (Q4) when compared to CD women. Additionally, sexual interest and satisfaction scores were positively associated with disease-specific quality of life.

Increasing levels of depression, anxiety, fatigue, sleep disturbance, and pain interference were associated with decreased sexual interest and satisfaction, and the magnitude and strength of each of these associations was independent of gender and disease type. 


\section{Additional Associations}

Prednisone use and perianal disease did not greatly impact interest and satisfaction scores, even though $\mathrm{CD}$ women with current steroid use had a lower interest score (39 vs. 41, $\mathrm{p}=0.04)$. Having an ostomy was also not associated with lower sexual interest or satisfaction. Finally, among UC patients, sexual interest and satisfaction scores were identical for patients with and without IPAA.

\section{DISCUSSION}

Our data suggest that, while women and men with IBD report similar levels of interest in sexual activity compared to the general population, they experience significantly lower satisfaction with their sex lives than their counterparts in the US general population. Additionally, we found that sexual interest and satisfaction among IBD patients were directly associated with disease-specific quality of life. Interest in sexual activity and satisfaction with sex life decreased with older age (except in CD men), and women had lower interest in sexual activity compared to men. Sexual interest and satisfaction were inversely associated with disease activity as measured by self-reported symptom based disease activity indices (SCDAI and SCCAI), particularly among men. As anticipated, depression, anxiety, fatigue, sleep disturbance, and pain interference were associated with decreased interest and satisfaction scores. Perianal disease and presence of ostomy or IPAA did not impact either interest or satisfaction.

The findings from this study add to the limited literature focusing on specific aspects of sexual health among IBD patients. Differentiating between the various components of sexual health, such as interest and satisfaction, is important because there may not always be a positive correlation between them. For example, one study in IBD patients showed that despite an increase in vaginal dryness, dyspareunia, and pain after surgery that interfered with sexual function, there was no significant change in sexual desire or satisfaction [32]. Similar incongruent findings between satisfaction with sex life and indicators of sexual dysfunction (such as erectile dysfunction) were found in cancer patients [15].

Our results are consistent with another study that found lower sexual interest for women than men, as compared to the general population [10]. However, the overall satisfaction with sex life was lower in men compared to women in our study. The lack of difference in both interest and satisfaction between those with and without an ostomy or IPAA is similar to previous findings reported by Bambrick et al. [32]. The inverse association between interest in sexual activity and satisfaction with increasing disease activity was also observed in a study that focused on sexual function in German IBD patients [11]. Men in that study reported higher levels of erectile dysfunction with increasing disease activity; however, disease activity did not affect sexual function in women.

The association between concurrent anxiety and depressive symptoms and lower sexual interest and satisfaction is also consistent with emerging literature. Anxiety and depression are common in patients with IBD [33], and decreased interest in sex is a common symptom in patients with depression [34]. Our study as well as three surveys by Timmer et al. confirmed an inverse relationship between depression and sexual function $[5,9,11,12]$. It is 
possible that depression is more common in patients with IBD with a resultant decrease in interest in sexual activity and satisfaction with sex life. Alternatively, decreased sexual interest and satisfaction secondary to IBD itself may result in depression. It seems likely that both of these theorectical models exist in patients with IBD.

Our study has important strengths. First, we surveyed a well-characterized population of patients with IBD from an existing registry. The study was the largest to date to assess interest in sexual activity and satisfaction with sex life in patients with IBD with more than 2500 participants. Although we did not do an a. priori sample size determination, the large study population provided a high degree of statistical power and precision for our analyses. Our study is also the only one to our knowledge that reports on these specific aspects of sexual health in patients in the US, except for one retrospective series of patients before and after IPAA. In addition, the high survey response rate (68\%) likely reduced reporting bias, and using an electronic survey instead of a face-to-face survey likely decreased reticence among participants to answer questions about sex. Lastly, we used a rigorously tested and validated measure, PROMIS SexFS, to measure interest in sexual activity and satisfaction with sex life, that offers a built-in comparison to US general population norms.

Despite the numerous strengths of the study, several limitations exist. First, as we sampled a volunteer-based cohort, our results may not be generalizable to the IBD community at large in the US. As the study was cross-sectional, we could not evaluate the causality of any of the associations between sexual interest and satisfaction an other indicators of disease severity or patient reported outcomes. Longitudinal studies are needed to further explore the impact of clinical factors and medical and/or surgical treatments on subsequent sexual interest and satisfaction. An additional limitation is that the diagnosis of IBD within our cohort is by self-report. Therefore, it is possible that misclassification exists. However, in a validation study including a random sample from CCFA Partners, $>97 \%$ had their IBD diagnosis confirmed by medical records [23]. Similarly, although we assessed disease activity through self-reported, symptom based indices, it was not practical to perform endoscopic assessment. Finally, other variables relevant to sexual health such as number of sex partners and information on body image were not collected in this study and should be included in future investigatons.

Our findings raise awareness of the scope of the problem of sexual health among IBD patients in the US and identify a health issue that many patients may be embarrassed to discuss with their provider. Accordingly, providers should consider querying patients about how their IBD might be affecting their sex life. Such conversations could be facilitated by the administration of measures such as the PROMIS SexFS. If problems pertaining to sexual interest and satisfaction are identified by clinicians, targeted treatment of active disease, management of concurrent psychiatric disease, and selected referral to providers specializing in sexual disorders may improve these important health domains and lead to an improved overall quality of life.

\section{Supplementary Material}

Refer to Web version on PubMed Central for supplementary material. 


\section{Acknowledgments}

Grant Support: This research was supported, in part, by a grant from the Crohn's and Colitis Foundation of America and support from the National Institutes of Health P30 DK034987 and T32DK07634. Kathryn Flynn was funded in part by the Research and Education Program Fund, a component of the Advancing a Healthier Wisconsin endowment at the Medical College of Wisconsin.

Guarantor of the article: Michael D. Kappelman

Specific author contributions (all authors approved the final draft submitted):

SE: interpretation of data; drafting of the manuscript; critical revision of the manuscript for important intellectual content.

RC: interpretation of data; drafting of the manuscript; critical revision of the manuscript for important intellectual content.

CM: study concept and design; data collection; acquisition of data; analysis and interpretation of data; critical revision of the manuscript for important intellectual content; statistical analysis.

KW: study design; analysis and interpretation of data; critical revision of the manuscript for important intellectual content

KF: study design; analysis and interpretation of data; critical revision of the manuscript for important intellectual content

MDL: study design; data collection; analysis and interpretation of data; critical revision of the manuscript for important intellectual content.

WC: data collection; critical revision of the manuscript for important intellectual content.

KA: data collection; critical revision of the manuscript for important intellectual content.

RSS: study design; data collection; analysis and interpretation of data; critical revision of the manuscript for important intellectual content.

MDK: study concept and design; data collection; analysis and interpretation of data; drafting of the manuscript; critical revision of the manuscript for important intellectual content.

\section{References}

1. Tribbick D, Salzberg M, Ftanou M, et al. Prevalence of mental health disorders in inflammatory bowel disease: an Australian outpatient cohort. Clin Exp Gastroenterol. 2015; 8:197-204. [PubMed: 26213474]

2. Fuller-Thomson E, Lateef R, Sulman J. Robust Association Between Inflammatory Bowel Disease and Generalized Anxiety Disorder: Findings from a Nationally Representative Canadian Study. Inflamm Bowel Dis. 2015

3. Grimstad T, Norheim KB, Isaksen K, et al. Fatigue in Newly Diagnosed Inflammatory Bowel Disease. Journal of Crohn's \& colitis. 2015

4. Norton C, Czuber-Dochan W, Bassett P, et al. Assessing fatigue in inflammatory bowel disease: comparison of three fatigue scales. Aliment Pharmacol Ther. 2015; 42:203-211. [PubMed: 25989464]

5. Timmer A, Bauer A, Dignass A, Rogler G. Sexual function in persons with inflammatory bowel disease: a survey with matched controls. Clin Gastroenterol Hepatol. 2007; 5:87-94. [PubMed: 17234557]

6. Moody GA, Mayberry JF. Perceived sexual dysfunction amongst patients with inflammatory bowel disease. Digestion. 1993; 54:256-260. [PubMed: 8243839]

7. Moody G, Probert CS, Srivastava EM, Rhodes J, Mayberry JF. Sexual dysfunction amongst women with Crohn's disease: a hidden problem. Digestion. 1992; 52:179-183. [PubMed: 1459352] 
8. Riviere P, Zallot C, Desobry P, et al. Frequency of and Factors Associated With Sexual Dysfunction in Patients With Inflammatory Bowel Disease. Journal of Crohn's \& colitis. 2017; 11:1347-1352.

9. Bel LG, Vollebregt AM, Van der Meulen-de Jong AE, et al. Sexual Dysfunctions in Men and Women with Inflammatory Bowel Disease: The Influence of IBD-Related Clinical Factors and Depression on Sexual Function. J Sex Med. 2015; 12:1557-1567. [PubMed: 26054013]

10. Marin L, Manosa M, Garcia-Planella E, et al. Sexual function and patients' perceptions in inflammatory bowel disease: a case-control survey. J Gastroenterol. 2013; 48:713-720. [PubMed: 23124604]

11. Timmer A, Bauer A, Kemptner D, Furst A, Rogler G. Determinants of male sexual function in inflammatory bowel disease: a survey-based cross-sectional analysis in $280 \mathrm{men}$. Inflamm Bowel Dis. 2007; 13:1236-1243. [PubMed: 17508419]

12. Timmer A, Kemptner D, Bauer A, Takses A, Ott C, Furst A. Determinants of female sexual function in inflammatory bowel disease: a survey based cross-sectional analysis. BMC Gastroenterol. 2008; 8:45. [PubMed: 18834529]

13. Cornish J, Wooding K, Tan E, Nicholls RJ, Clark SK, Tekkis PP. Study of sexual, urinary, and fecal function in females following restorative proctocolectomy. Inflamm Bowel Dis. 2012; 18:16011607. [PubMed: 22275287]

14. Wang JY, Hart SL, Wilkowski KS, et al. Gender-specific differences in pelvic organ function after proctectomy for inflammatory bowel disease. Dis Colon Rectum. 2011; 54:66-76. [PubMed: 21160316]

15. Flynn KE, Jeffery DD, Keefe FJ, et al. Sexual functioning along the cancer continuum: focus group results from the Patient-Reported Outcomes Measurement Information System (PROMIS(R)). Psychooncology. 2011; 20:378-386. [PubMed: 20878833]

16. Flynn KE, Lin L, Cyranowski JM, et al. Development of the NIH PROMIS (R) Sexual Function and Satisfaction measures in patients with cancer. J Sex Med. 2013; 10(Suppl 1):43-52. [PubMed: 23387911]

17. Weinfurt KP, Lin L, Bruner DW, et al. Development and Initial Validation of the PROMIS((R)) Sexual Function and Satisfaction Measures Version 2.0. J Sex Med. 2015; 12:1961-1974. [PubMed: 26346418]

18. Flynn KE, Reeve BB, Lin L, Cyranowski JM, Bruner DW, Weinfurt KP. Construct validity of the PROMIS(R) sexual function and satisfaction measures in patients with cancer. Health and quality of life outcomes. 2013; 11:40. [PubMed: 23497200]

19. Alexander AM, Flynn KE, Hahn EA, et al. Improving patients' understanding of terms and phrases commonly used in self-reported measures of sexual function. J Sex Med. 2014; 11:1991-1998. [PubMed: 24902984]

20. Fortune-Greeley AK, Flynn KE, Jeffery DD, et al. Using cognitive interviews to evaluate items for measuring sexual functioning across cancer populations: improvements and remaining challenges. Qual Life Res. 2009; 18:1085-1093. [PubMed: 19672697]

21. Jeffery DD, Tzeng JP, Keefe FJ, et al. Initial report of the cancer Patient-Reported Outcomes Measurement Information System (PROMIS) sexual function committee: review of sexual function measures and domains used in oncology. Cancer. 2009; 115:1142-1153. [PubMed: 19195044]

22. Long MD. Development of an internet-based cohort of patients with inflammatory bowel diseases (CCFA Partners): methodology and initial results. Inflamm Bowel Dis. 2012; 18:2099-2106. [PubMed: 22287300]

23. Randell RL, Long MD, Cook SF, et al. Validation of an internet-based cohort of inflammatory bowel disease (CCFA partners). Inflamm Bowel Dis. 2014; 20:541-544. [PubMed: 24451221]

24. Rothrock NE, Hays RD, Spritzer K, Yount SE, Riley W, Cella D. Relative to the general US population, chronic diseases are associated with poorer health-related quality of life as measured by the Patient-Reported Outcomes Measurement Information System (PROMIS). J Clin Epidemiol. 2010; 63:1195-1204. [PubMed: 20688471]

25. Reeve BB, Hays RD, Bjorner JB, et al. Psychometric evaluation and calibration of health-related quality of life item banks: plans for the Patient-Reported Outcomes Measurement Information System (PROMIS). Med Care. 2007; 45:S22-31. [PubMed: 17443115] 
26. Colangelo KJ, Pope JE, Peschken C. The minimally important difference for patient reported outcomes in systemic lupus erythematosus including the HAQ-DI, pain, fatigue, and SF-36. J Rheumatol. 2009; 36:2231-2237. [PubMed: 19723907]

27. Hays RD, Spritzer KL, Fries JF, Krishnan E. Responsiveness and minimally important difference for the patient-reported outcomes measurement information system (PROMIS) 20-item physical functioning short form in a prospective observational study of rheumatoid arthritis. Ann Rheum Dis. 2015; 74:104-107. [PubMed: 24095937]

28. Lee AC, Driban JB, Price LL, Harvey WF, Rodday AM, Wang C. Responsiveness and Minimally Important Differences for 4 Patient-Reported Outcomes Measurement Information System Short Forms: Physical Function, Pain Interference, Depression, and Anxiety in Knee Osteoarthritis. J Pain. 2017

29. Irvine EJ, Zhou Q, Thompson AK. The Short Inflammatory Bowel Disease Questionnaire: a quality of life instrument for community physicians managing inflammatory bowel disease. CCRPT Investigators. Canadian Crohn's Relapse Prevention Trial. Am J Gastroenterol. 1996; 91:1571-1578. [PubMed: 8759664]

30. Thia K, Faubion WA Jr, Loftus EV Jr, Persson T, Persson A, Sandborn WJ. Short CDAI: development and validation of a shortened and simplified Crohn's disease activity index. Inflamm Bowel Dis. 2011; 17:105-111. [PubMed: 20629100]

31. Jowett SL, Seal CJ, Phillips E, Gregory W, Barton JR, Welfare MR. Defining relapse of ulcerative colitis using a symptom-based activity index. Scand J Gastroenterol. 2003; 38:164-171. [PubMed: 12678333]

32. Bambrick M, Fazio VW, Hull TL, Pucel G. Sexual function following restorative proctocolectomy in women. Dis Colon Rectum. 1996; 39:610-614. [PubMed: 8646943]

33. Faust AH, Halpern LF, Danoff-Burg S, Cross RK. Psychosocial factors contributing to inflammatory bowel disease activity and health-related quality of life. Gastroenterol Hepatol (N Y). 2012; 8:173-181. [PubMed: 22675279]

34. Kennedy SH, Dickens SE, Eisfeld BS, Bagby RM. Sexual dysfunction before antidepressant therapy in major depression. J Affect Disord. 1999; 56:201-208. [PubMed: 10701478] 


\section{Table 1}

Characteristics of the Study Population

\begin{tabular}{|c|c|c|c|c|}
\hline & Characteristics & $\begin{array}{l}\mathrm{CD}(\mathrm{n}=1639) \\
\text { Mean (SD) or \% }\end{array}$ & $\begin{array}{l}\text { UC(n=930) } \\
\text { Mean (SD) or \% }\end{array}$ & $\begin{array}{l}\text { Overall IBD }(n=2569) \\
\text { Mean }(\mathrm{SD}) \text { or } \%\end{array}$ \\
\hline \multirow[t]{15}{*}{ Demographics } & Age, years & $42(14)$ & $42(14)$ & $42(14)$ \\
\hline & Female sex & 72 & 69 & 71 \\
\hline & Race/ethnicity & & & \\
\hline & White & 93 & 88 & 91 \\
\hline & African American & 3 & 2 & 3 \\
\hline & Asian & 0.3 & 3 & 2 \\
\hline & Other & 4 & 6 & 5 \\
\hline & Hispanic & 3 & 5 & 4 \\
\hline & Education completed & & & \\
\hline & $<12$ th grade & 1 & 0.4 & 1 \\
\hline & 12 th grade & 7 & 5 & 6 \\
\hline & Some college & 22 & 18 & 20 \\
\hline & College & 43 & 43 & 43 \\
\hline & Graduate school & 28 & 34 & 31 \\
\hline & Current smoker & 10 & 8 & 9 \\
\hline \multirow[t]{7}{*}{ Disease Characteristics } & Disease Duration & $15(12)$ & $11(10)$ & $13(11)$ \\
\hline & $\begin{array}{l}\geq 1 \text { hospitalizationsin } \\
\text { the past year }\end{array}$ & 19 & 11 & 16 \\
\hline & $\geq 1$ bowel surgery & 52 & 15 & 39 \\
\hline & IPAA or Koch pouch & 3 & 10 & 6 \\
\hline & Ostomy & 9 & 5 & 7 \\
\hline & sCDAI or SCCAI & $153(100)$ & $4(3)$ & $\mathrm{n} / \mathrm{a}$ \\
\hline & SIBDQ & $5(1)$ & $5(1)$ & $5(1)$ \\
\hline \multirow[t]{4}{*}{ Current Medication Use } & 5-aminosalicylates & 34 & 66 & 46 \\
\hline & Prednisone & 9 & 13 & 10 \\
\hline & Immunomodulators $^{a}$ & 28 & 23 & 26 \\
\hline & Biologic therapy $b$ & 42 & 19 & 34 \\
\hline \multirow[t]{7}{*}{ General PROMIS ${ }^{c}$ Measures } & Anxiety & $54(10)$ & $55(9)$ & $55(10)$ \\
\hline & Depression & $52(10)$ & $52(10)$ & $52(10)$ \\
\hline & Fatigue & $57(11)$ & $55(11)$ & $56(11)$ \\
\hline & Sleep Disturbance & $52(9)$ & $52(9)$ & $52(9)$ \\
\hline & Satisfaction with Social & $47(10)$ & $48(10)$ & $48(10)$ \\
\hline & Role & & & \\
\hline & Pain & $54(10)$ & $52(10)$ & $53(10)$ \\
\hline \multirow[t]{3}{*}{ Sexually active ${ }^{d}$} & Yes & 76 & 78 & 77 \\
\hline & Male & 77 & 78 & 78 \\
\hline & Female & 76 & 79 & 77 \\
\hline
\end{tabular}

Dig Dis Sci. Author manuscript; available in PMC 2019 June 01. 
$b_{\text {Infliximab, adalimumab, certolizumab pegol, or natalizumab. }}$

${ }^{c}$ Patient Reported Outcome Information Measurement System items are calibrated so that the mean of the US general population is 50 and the standard.

${ }^{d}$ Sexually active within past 30 days. 


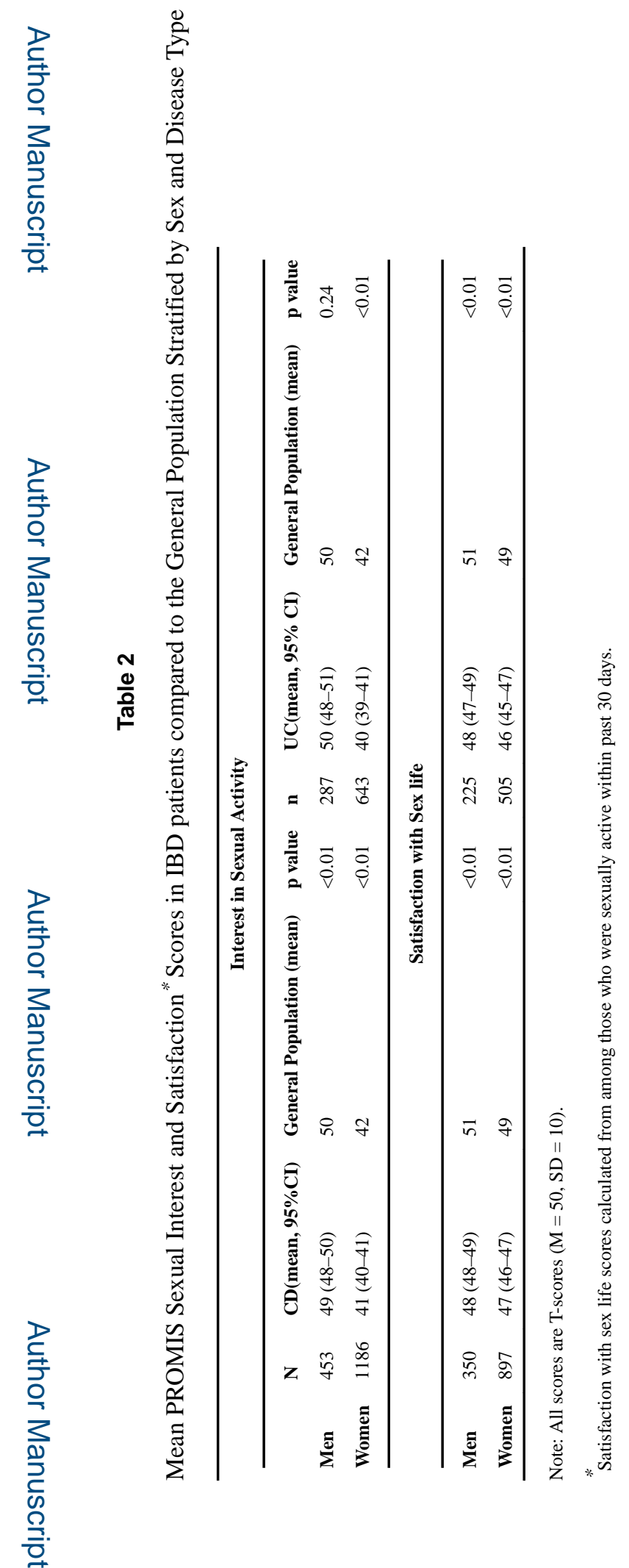

Dig Dis Sci. Author manuscript; available in PMC 2019 June 01. 


\section{롤 \\ }

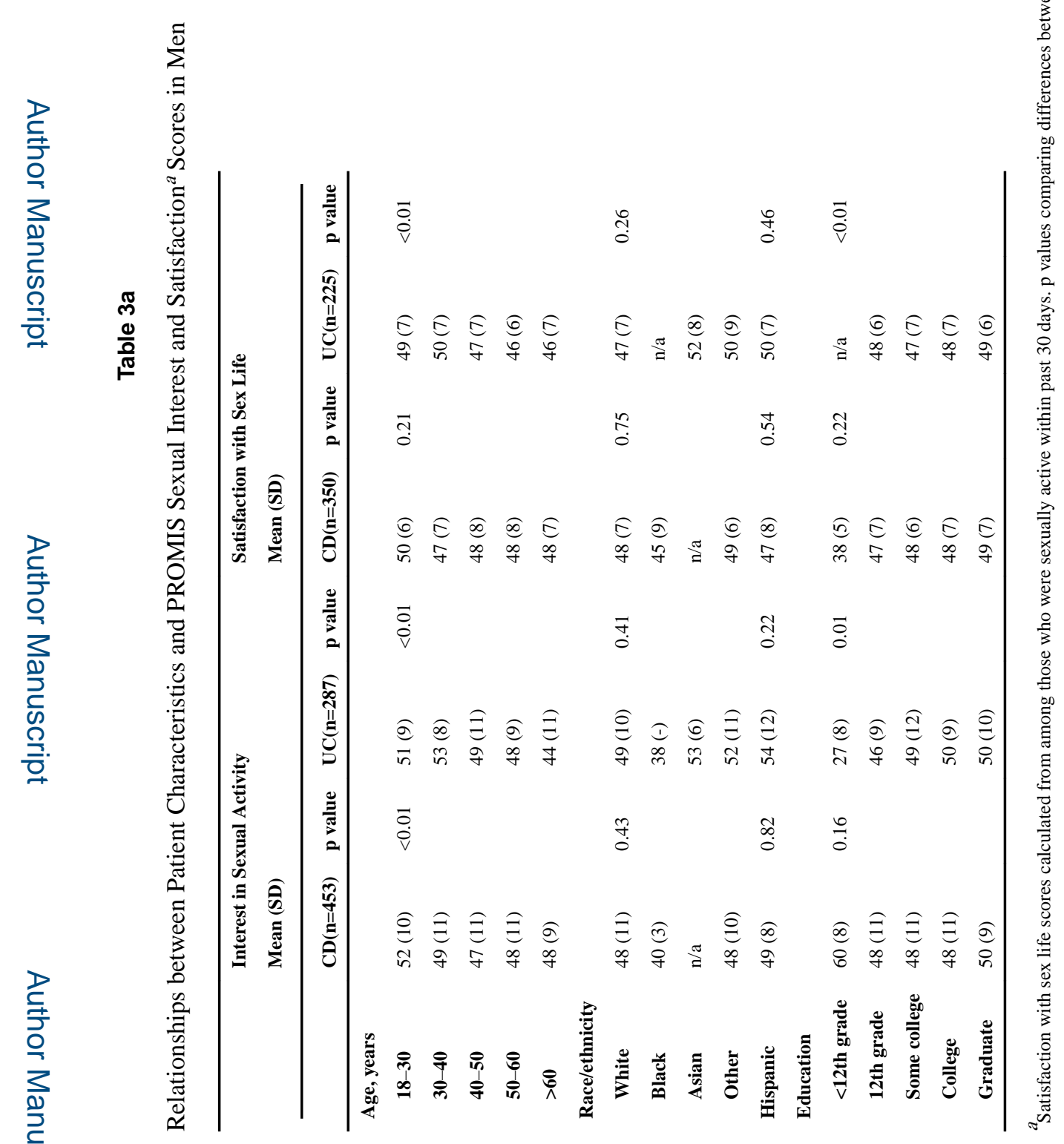

Dig Dis Sci. Author manuscript; available in PMC 2019 June 01. 


\section{롬 \\ 일}

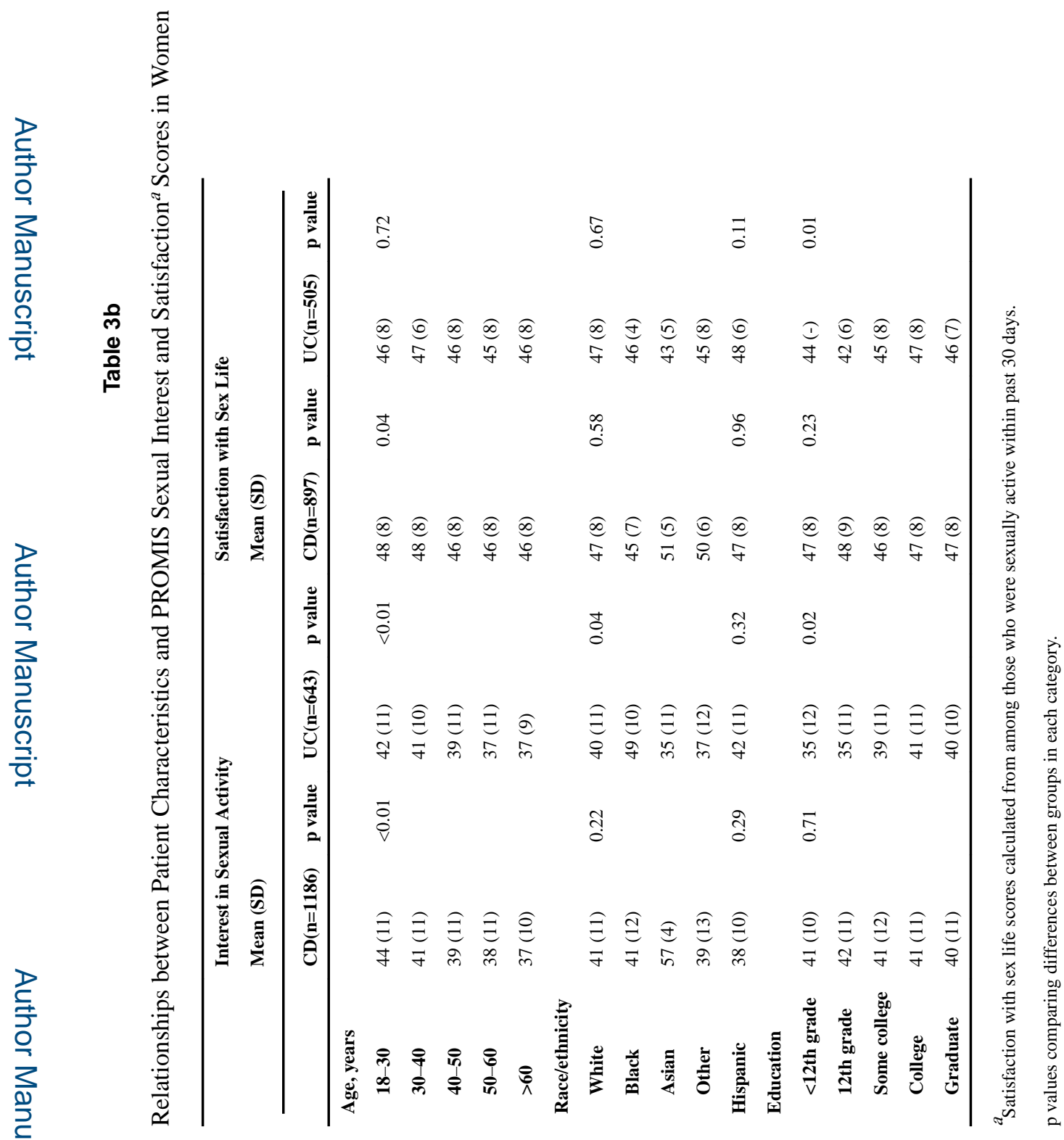

Dig Dis Sci. Author manuscript; available in PMC 2019 June 01. 


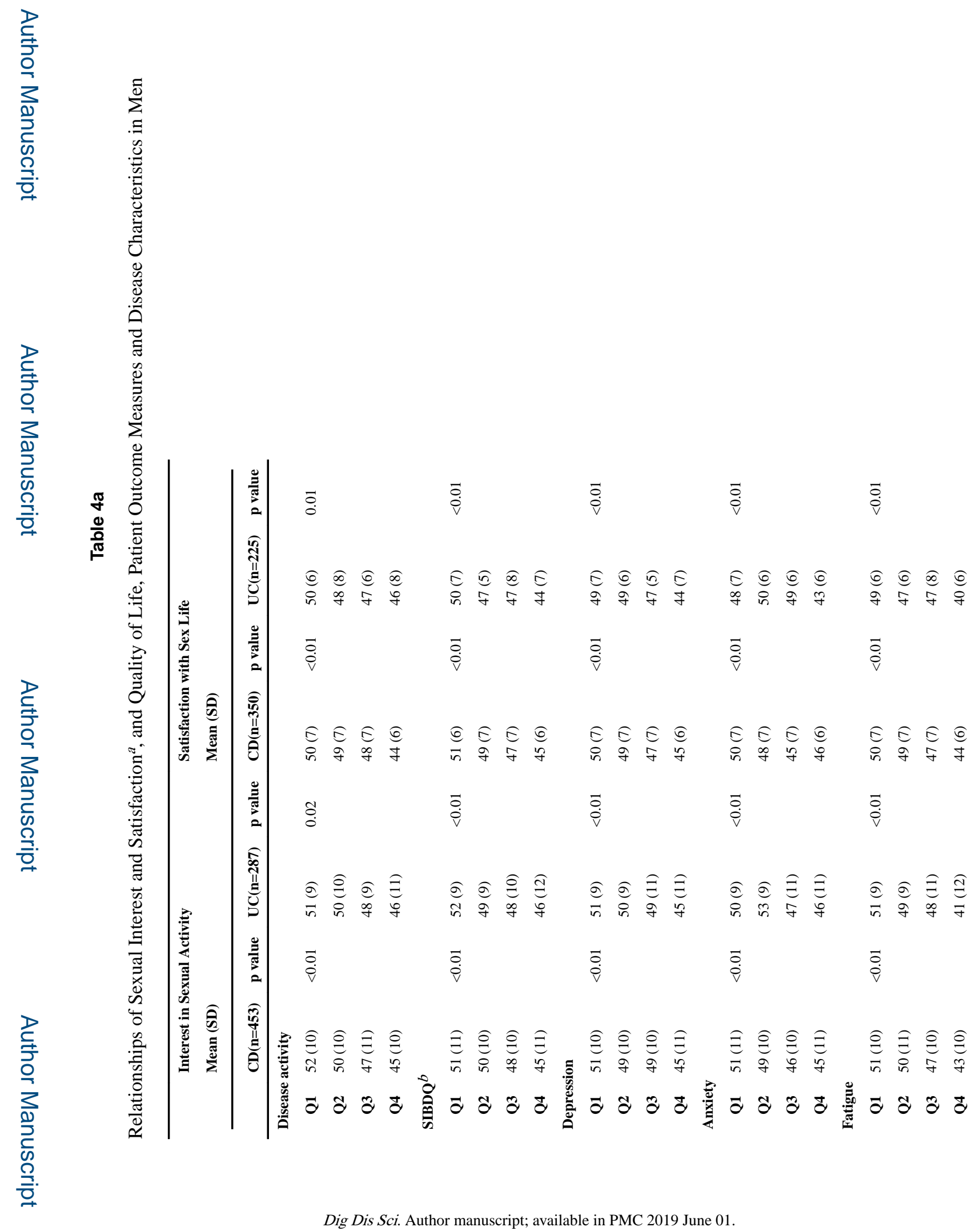




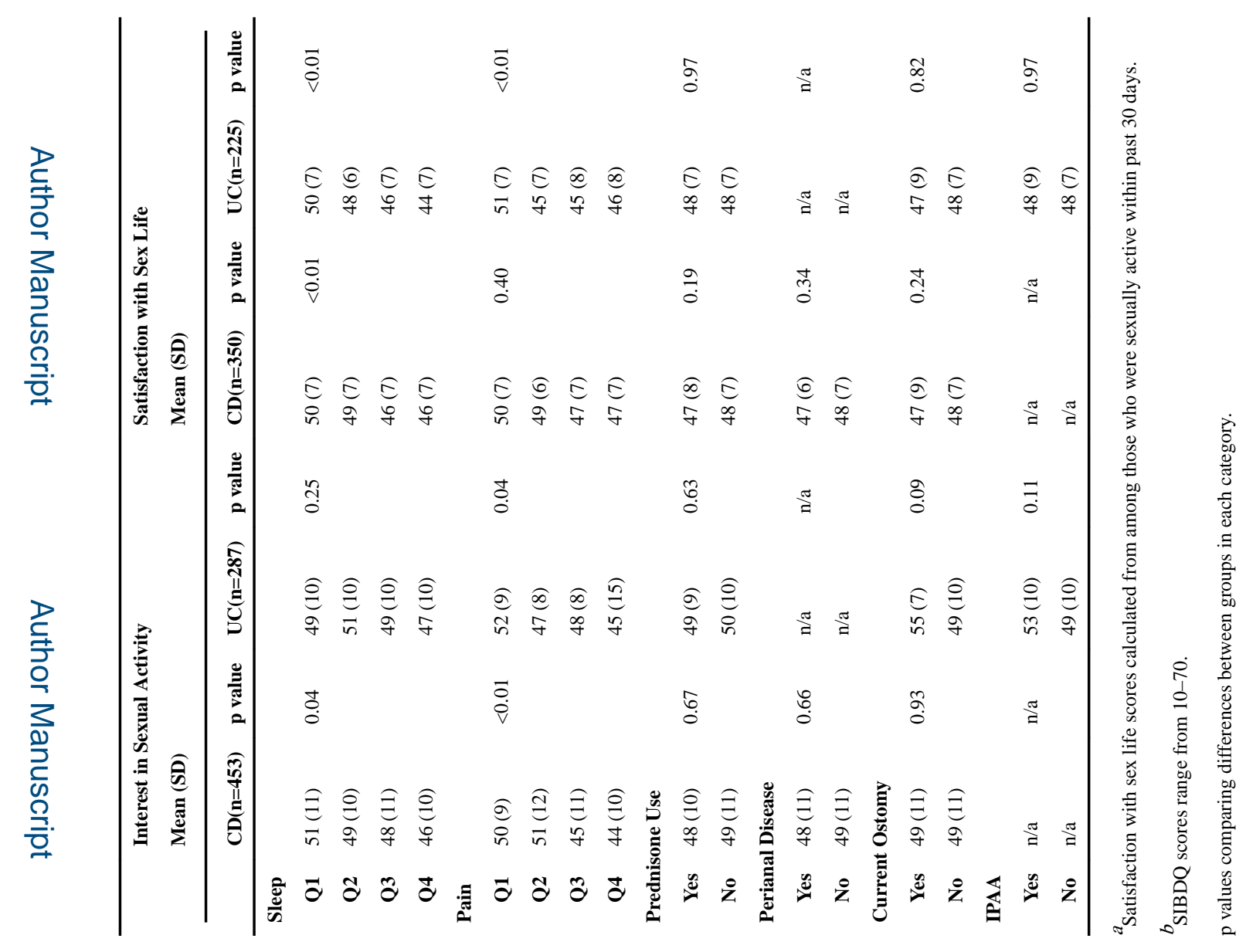

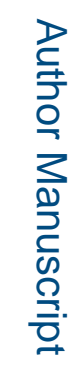

로을

Dig Dis Sci. Author manuscript; available in PMC 2019 June 01. 


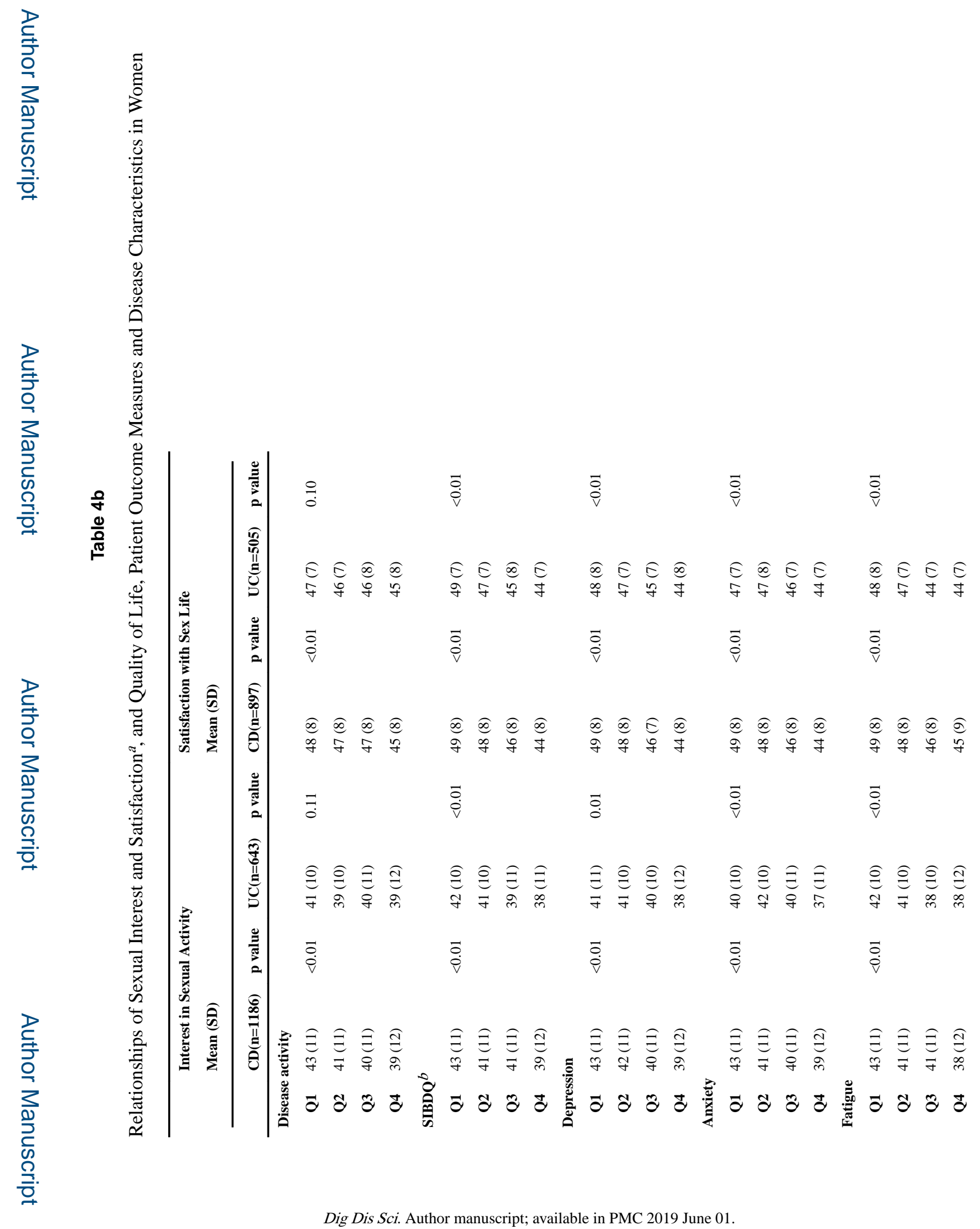




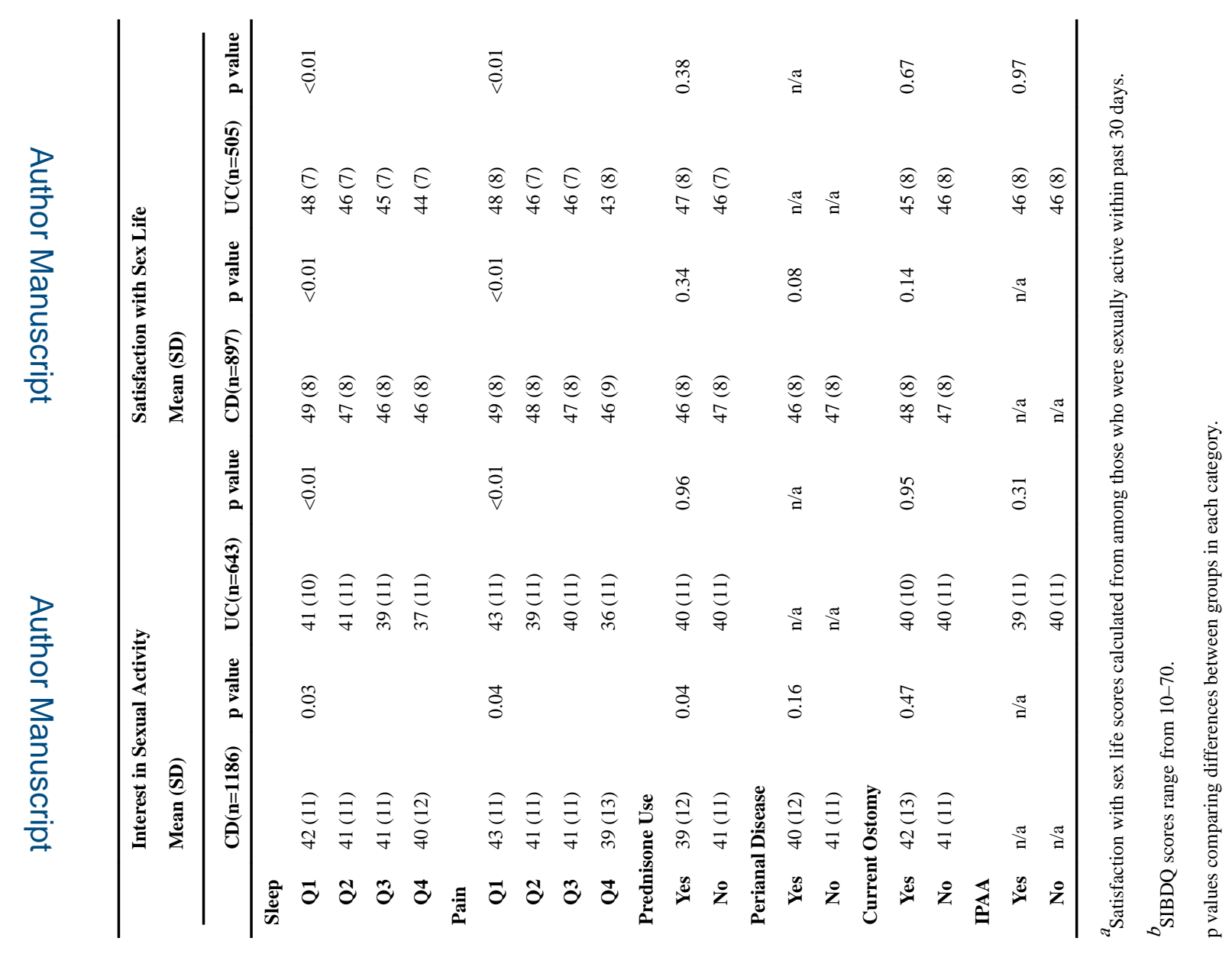

로을

로을

Dig Dis Sci. Author manuscript; available in PMC 2019 June 01. 